\title{
FUZZY LOGIC MODEL FOR MULTI - PURPOSE MULTI - RESERVOIR SYSTEM
}

\author{
Mynepally.Anjaneya Prasad and S.Mohan \\ Environmental and Water Resources Division, Indian Institute of Technology Madras \\ Chennai - 600036 India
}

Abstract: Reservoirs are built usually to serve multiple purposes. viz. irrigation, municipal and industrial water supply, hydro-power and flood control. Due to high variability of annual rainfall and conflicting demands on scarce water resources, the study and operation of reservoir systems has assumed great significance to meet the short term and long-term requirements. The reservoir managers do not find previous techniques of complex optimization models are difficult to adopt practically. New methods have to be developed which are simple to understand and can be effectively adopted for the existing systems. Any reservoir problem is usually site specific in nature and hence any general modeling methodology cannot be directly applied to study the system behavior. Artificial intelligence approaches are now being adopted to effectively simulate the reservoir system based on the experience of human knowledge and expertise. These methods are simple to understand for the reservoir managers and also may be acceptable since the model is being developed with the output and opinion of experts who are really operating the reservoir system. The Fuzzy rule based systems are very much suitable for inferring developed operating policies. In the present work a rule based fuzzy model is attempted for long-term operation a multi reservoir system. The present model was developed on monthly basis for operation and the model was demonstrated with a case of two serial reservoirs on River Godavari sub system located in South India when they are operated individually. The recent artificial intelligence tools like Genetic programming, Artificial Neural networks and Fuzzy logic are increasingly used as soft computing techniques to address modelling issues. The main advantage of these techniques lies in handling noisy data, addressing non - linear and dynamic systems. These tools also useful when it is difficult to explain the physical relationship are not fully understood in order to enhance the performance of the system.

The present paper is aimed to present a fuzzy logic methodology for long-term reservoir operation. In this method a monthly fuzzy rule based model was 
developed based on the historical operation. The performance of the model was tested with calibrated period and validation period.

Keywords: Reservoirs, System, long-term operation, Fuzzy logic, Artificial intelligence, soft computing techniques.

\section{INTRODUCTION}

The purpose of this paper is to develop a fuzzy rule-based method for constructing reservoir operation rules. A case study of two serially connected reservoirs is used to illustrate the approach when the reservoirs are operated on individual basis. In fuzzy rule base system the operating rules are inferred from historical operation and hence the experience of operator can be in-built into the system. Fuzzy sets provides by means of translating linguistic descriptors into usable numerical values. Probability law does not bind the uncertainty and vagueness. Savic and Simonovic (1991) used fuzzy set method to model for a chance constrained reservoir operation for selecting risk levels. Shrestha et al (1996) proposed that inputs to the reservoir operating principles (e.g. initial storage, inflows, and demands), as well as outputs (historical releases) could be described by fuzzy relations. These fuzzy inputs and are combined to produce fuzzy output relation, which can be combined and defuzzified to get crisp output. Panigrahi and Mujumdar (2000) attempted a fuzzy rule based model for a single reservoir operation. In their methodology they adopted a Stochastic Dynamic Programming (SDP) for framing rule base. Cheng Chuntain (1999) adopted a fuzzy optimal model for real time flood operation for multireservoirs. Jolma et al attempted a fuzzy logic model for operation of five lakes. They attempted based on general knowledge to mimic human operator and presented two types of approaches based on case-based reasoning and a rule based reasoning. Durbovin et al (2002) presented a real time reservoir operation model based on total fuzzy similarity and compared with fuzzy inference method known as Sugeno-style fuzzy inference.

The present paper is aimed to present a fuzzy logic methodology for long-term reservoir operation. In this method a monthly fuzzy rule based model has been developed based on the historical Operation and the rules were derived for the two reservoirs on Godavari river system in South India

\section{FUZZY RULE BASED SYSTEM}

A fuzzy rule based model is a mathematical model based on a fuzzy rule system. In a fuzzy rule system if ' $\mathfrak{R}$ ' is defined as a set of rules which 
consists of set of input variables or premises, $A_{i, k}$ in the form of fuzzy sets with membership functions $\mu_{\mathrm{Ai}, \mathrm{k}}$ and a set of consequences $\mathrm{B}_{\mathrm{i}}$ also in the form of fuzzy sets.

For example, in a reservoir operation system, the premises may be of storage at the beginning of time period, inflows and the consequences of these variables are releases. Based on expert opinion or from historical operation the rules can be constructed. In the present study the historical operation was taken for the development of rule base. The combined response of the rule surface is a fuzzy output, which is transformed into a single crisp value called defuzzification.

\subsection{Fuzzification of inputs}

Any reservoir performance depends on its operation policies, which in turn depend on the inputs like inflows and storage apart from system losses. Hence it is important that the deriving operational rules for enhancement of performance plays important role for the managers of reservoir. In the present study the inputs to the system are Inflows during the time period ' $t$ ' and Storage at the beginning of time period ' $t$ '. These are taken as fuzzy inputs and releases as fuzzy outputs to the model. Since inflows in any period are uncertain and the Storages are also uncertain due to variation of inflows and some times vague due to poor operation. These uncertainties and vagueness can be handled effectively by fuzzy logic modeling. The input values are always crisp numerical values limited to the universe of discourse of the input variable and the result of Fuzzification is called fuzzy degree of membership, which varies from 0 to 1 . The problem lies in construction of membership function so as to capture the meaning of all the associated operations in the linguistic terms. The construction of membership function was attempted by several researchers to capture expert opinion, use of optimal models and more recently from the historical operation itself so that the knowledge of operators can be taken for building the model which is acceptable to the reservoir managers. In the present study the historical operation was taken for modeling.

Fig 1 shows the transformation of inflow variable into fuzzy variable as an example. For an inflow value of $30 \mathrm{M} \mathrm{m}^{3}$ units the membership value is 0.8 when the variable lies in one class of input flows viz. Inflow is Low. Suppose if the input value is lying in two classes of inputs like inflow Low and Medium, the membership of both is considered and using centroid approach a single crisp membership value is calculated by the model. 


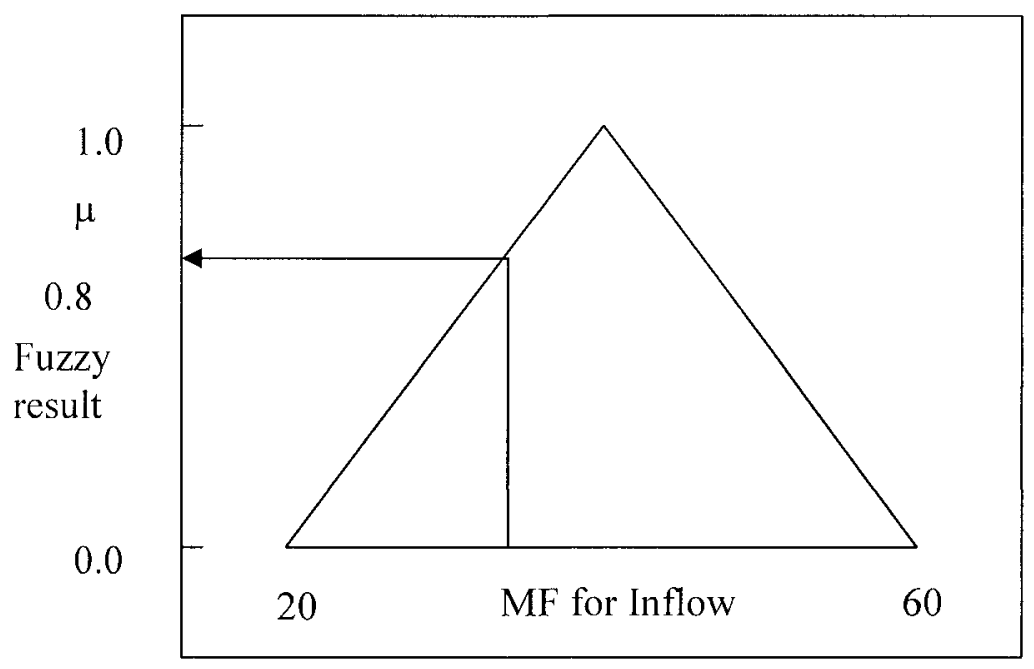

Fig 1. Fuzzy transformation of Input Inflow

\subsection{Formation of fuzzy rule base}

The fuzzy rule base was formed based on the historical operation and intuition or logically after studying the historical operation. From the historical operation a matrix of rule base was prepared based on the range of input parameters for all the months individually. Wherever the historical values were not available in any fuzzy range, the linguistic rules were developed based on logic and intuition. A fuzzy rule base may be in the form as follows.

If the storage is $\boldsymbol{m e d}$, and inflow is $\boldsymbol{h i g h}$ for the period ' $\mathrm{t}$ ', then the release is med.

\subsection{Aggregation}

Aggregation is the unification of output of each rule by joining them. If an input value correspond to both the membership functions, fuzzy rule corresponding to both the rules are invoked. Here each rule invokes after implication, specifies one fuzzy output set. Then two fuzzy output sets are then unified to get single output fuzzy set. 


\section{DEFUZZIFICATION METHOD}

The result obtained from the implication is in the form of a fuzzy set. This is defuzzified to get a crisp output. In the present study the most common defuzzified centroid method was adopted. In the centroid method of defuzzification the real value is computed by the equation given in 1 .

$$
G=\frac{\sum_{i=1}^{n} y_{i} m_{B}\left(y_{i}\right)}{\sum_{i=1}^{n} m_{B}\left(y_{i}\right)}
$$

where $G$ is the centroid of the truncated fuzzy output set $B . m_{B}\left(y_{i}\right)$ is the membership value of element $y_{i}$ in the fuzzy output set $B$, and $n$ is the number of elements. In this centroid method of defuzzification all values of output is used

The entire methodology applied for the model is shown in fig 2

\section{APPLICATION OF FUZZY MODEL TO RESERVOIRS CONSIDERED}

In the present study 31 years of historical data of inflow, storage and releases were collected at the reservoir. From this data 23 years of data was used for building the model and 8 years of data was used to test the model on monthly basis. A typical membership function for input and output variable is presented in fig.3. Similarly the membership functions for inflows, Storage and releases for Sri Rama Sagar reservoir were also developed for all months. The basic mass balance equation was used to simulate the performance of reservoirs is given in equation 2 .

$S_{n}^{t+1}=S_{n}^{t}+I_{n}^{t}-R_{n}^{t}-O_{n}^{t}-E_{n}^{t}$

where

$S_{n}^{t+1} \quad$ Storage at the beginning of time period $(t+1)$

$S_{n}^{t} \quad$ Storage at the beginning of time period $(t)$

$I_{n}^{t} \quad$ Inflow during the time period $(t)$

$R_{n}^{t} \quad$ Release during the time period $(t)$

$O_{n}^{t} \quad$ overflow at the during of time period

$E_{n}^{t} \quad$ Evaporation loss during the time period 


\section{PERFORMANCE OF NIZAMSAGAR RESERVOIR}

The Nizamsagar project is a multipurpose project catering to Irrigation, Hydropower and Water supply to the near by town. The reservoir has a capacity of $504 \mathrm{M} \mathrm{m}^{3}$ and a canal powerhouse with an installed capacity of 4 MW. The fuzzy simulation model was calibrated with 31 years of monthly data and validated with 8 years of data. To test the performance of this multi-purpose reservoir it was simulated for 5 years. For the computation of demands for irrigation Penman-Montieth method was adopted using cropwat software. The comparative performance of model with that of historical for irrigation is shown in fig 4 and fig 5 for Rabi and Kharief seasons. Fig 6 shows seasonal performance for water supply. Fig 7 shows the annual performance of Hydropower. The storage comparison for the period of simulation is shown in fig 8 . 


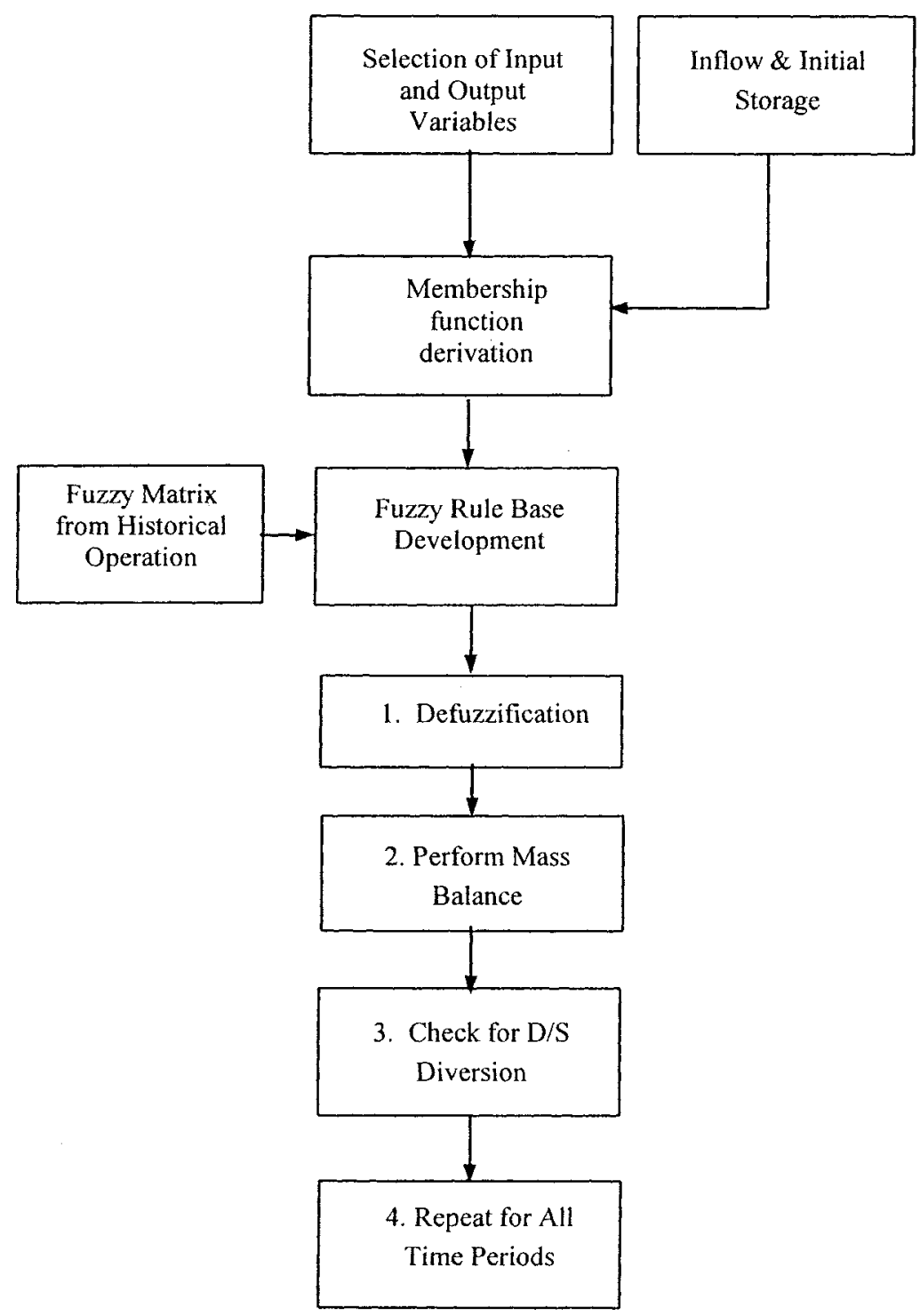

Fig 2 Flow Diagram of Fuzzy Logic Model for Reservoir Operation 


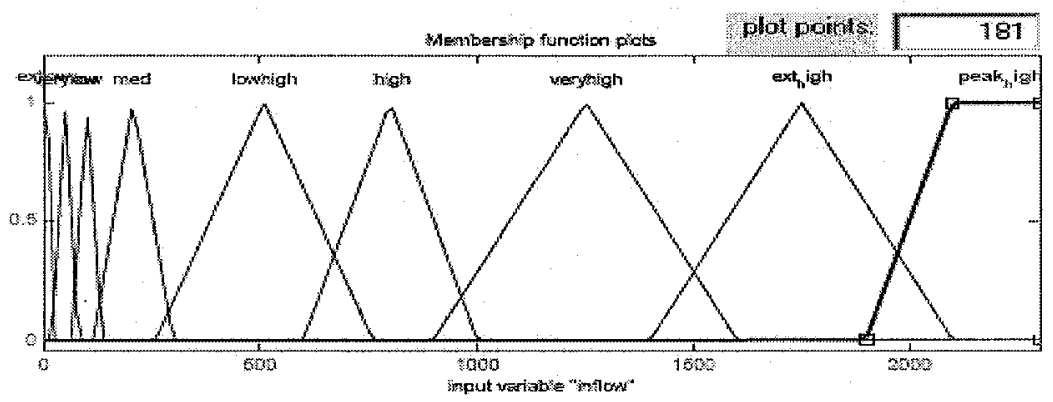

Membership function for Inflow during "August" at Nizamsagar

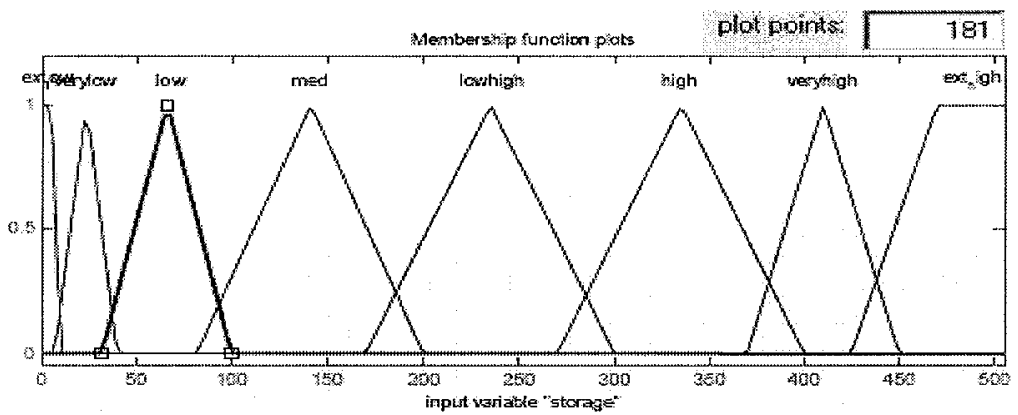

Membership function for Storage during "August" at Nizamsagar

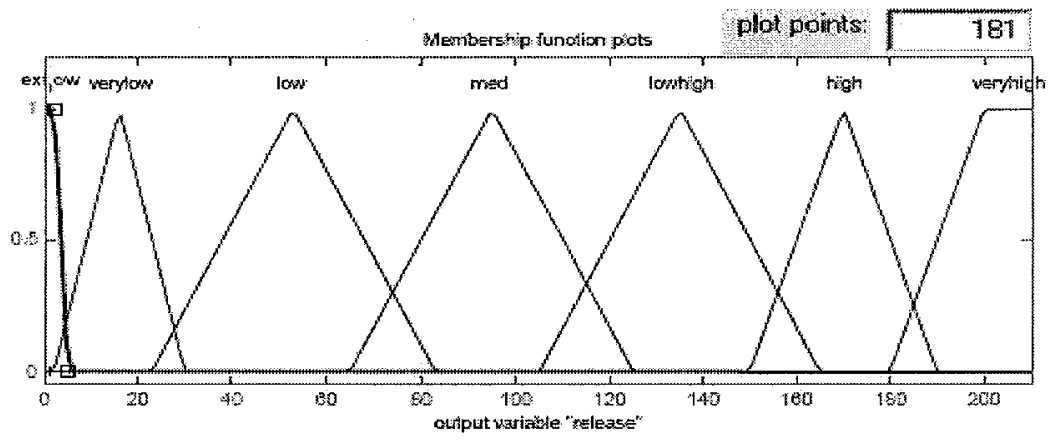

Membership function for Release during "August" at Nizamsagar

Fig 3 Membership functions for Input and Output Variables during "August" at Nizamsagar 


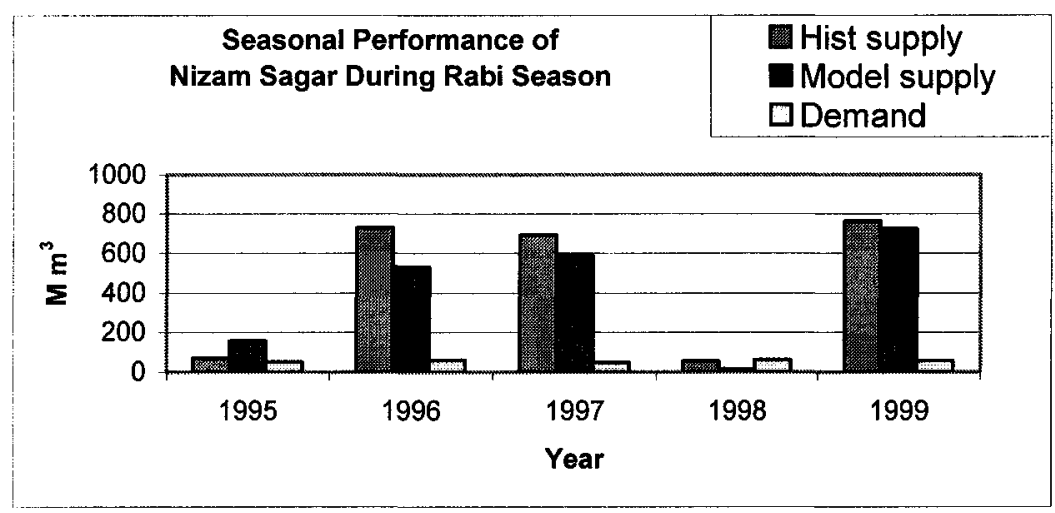

Fig 4 Nizamsagar Reservoir Rabi Performance

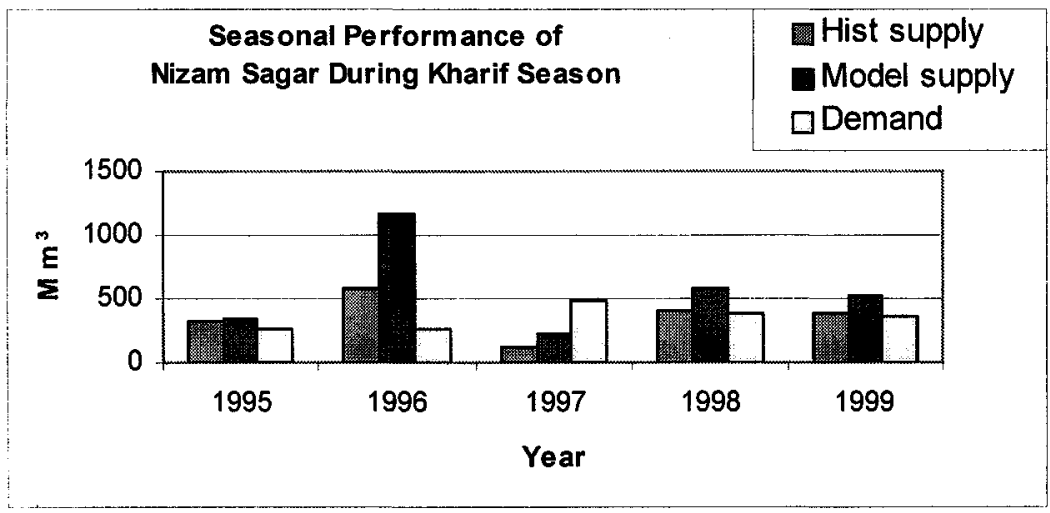

Fig 5 Nizamsagar Reservoir Kharif Performance

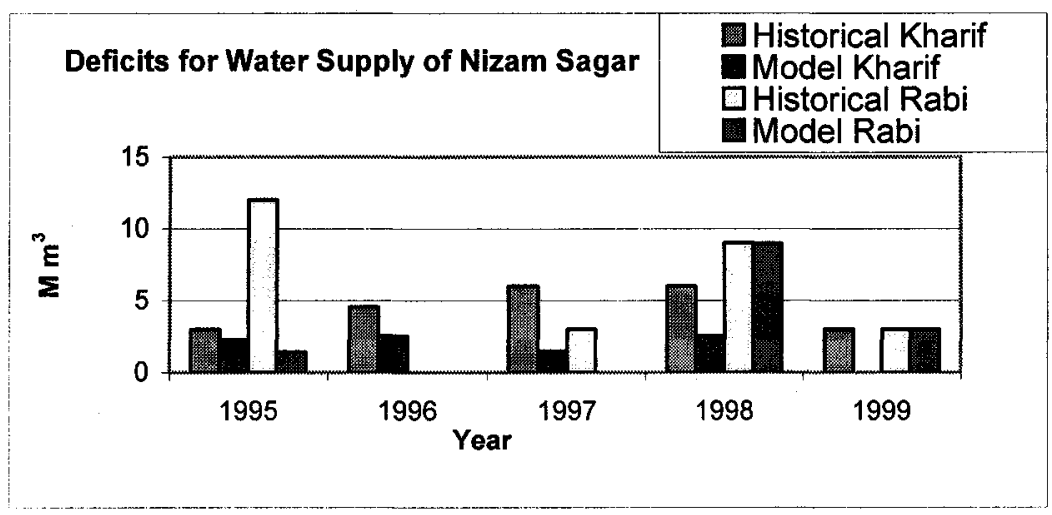

Fig 6. Performance of Nizamsagar for water supply 


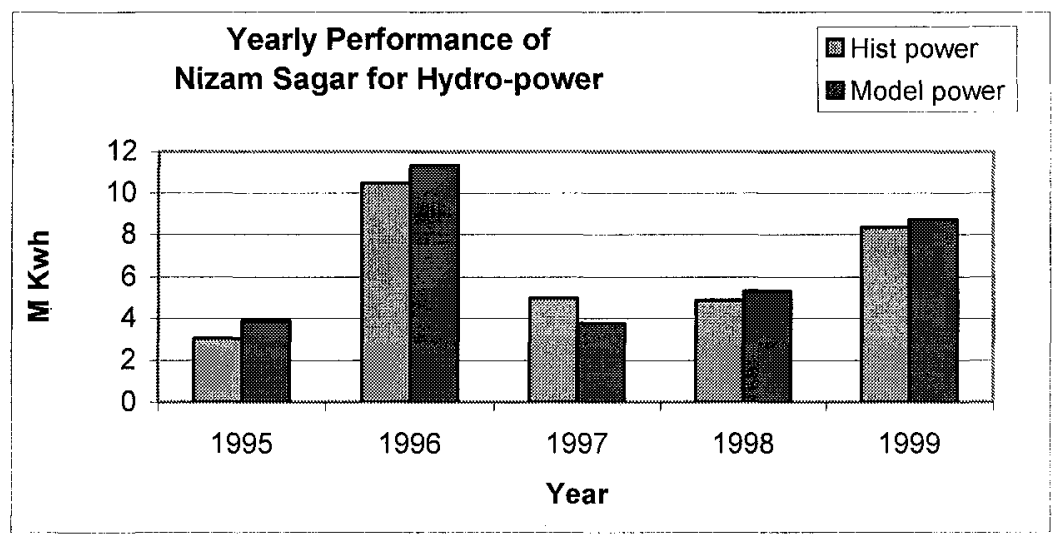

Fig 7. Performance of Annual Hydropower Production at Nizamsagar

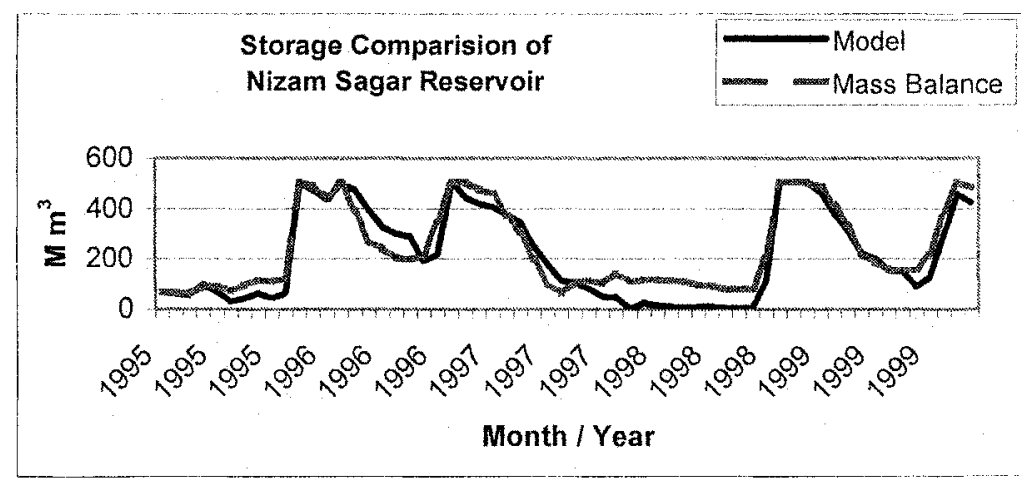

Fig 8. Variation of Storage Comparison at Nizamsagar

\section{PERFORMANCE OF SRIRAMSAGAR RESERVOIR}

The Sriramsagar project is a major multipurpose project catering to Irrigation, Hydropower and Water supply and industrial supply. The reservoir has a capacity of $3155 \mathrm{M} \mathrm{m}^{3}$ and a canal powerhouse with an installed capacity of $27 \mathrm{MW}$. The fuzzy simulation model was calibrated with 24 years of monthly data and validated with 6 years of data. To test the performance of this multi-purpose reservoir it was simulated for 5 years. For the computation of demands for irrigation Penman-Monteith method was 
adopted using cropwat software. The comparative performance of model with that of historical for irrigation is shown in fig 9 and fig 10 for Rabi and Kharief seasons. Fig 11 shows seasonal performance for water supply. Fig 12 shows the annual performance of Hydropower. The storage comparison for the period of simulation is shown in fig 13 .

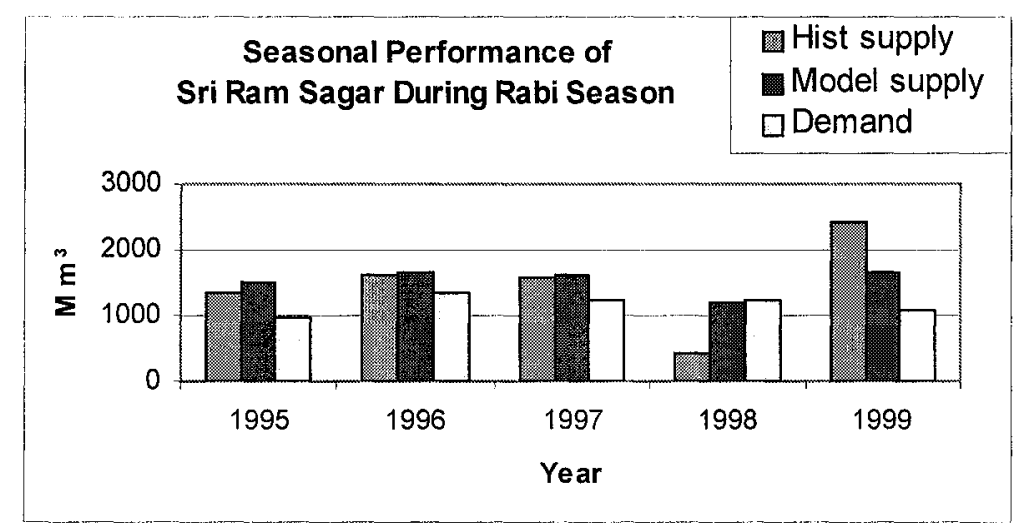

Fig 9 Sriramsagar Reservoir Rabi Performance

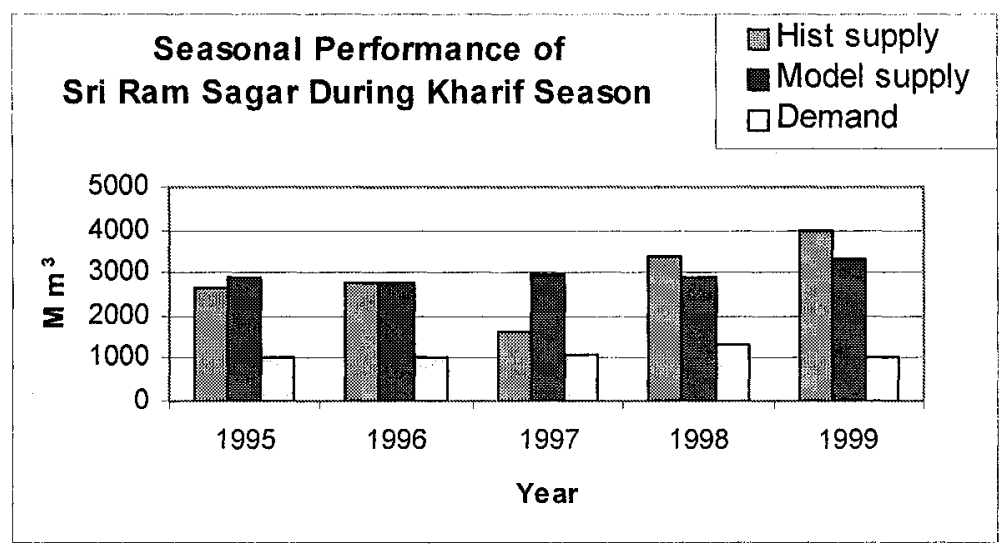

Fig 10 Sriramsagar Reservoir Kharief Performance 


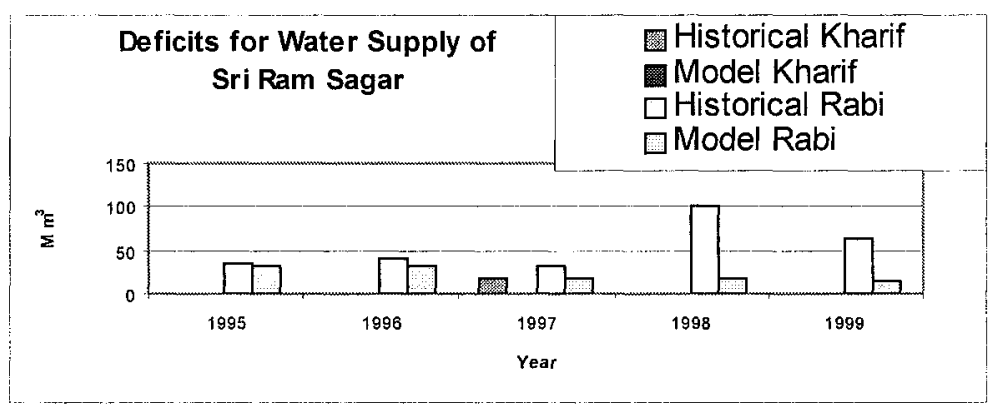

Fig 11 Sriramsagar Reservoir Performance for Water Supply

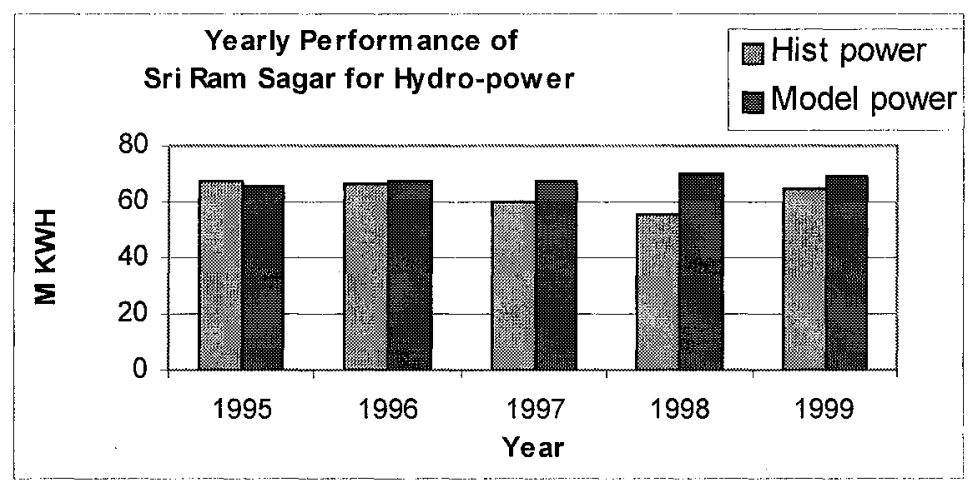

Fig 12 Sriramsagar Reservoir Annual Hydro Power Performance

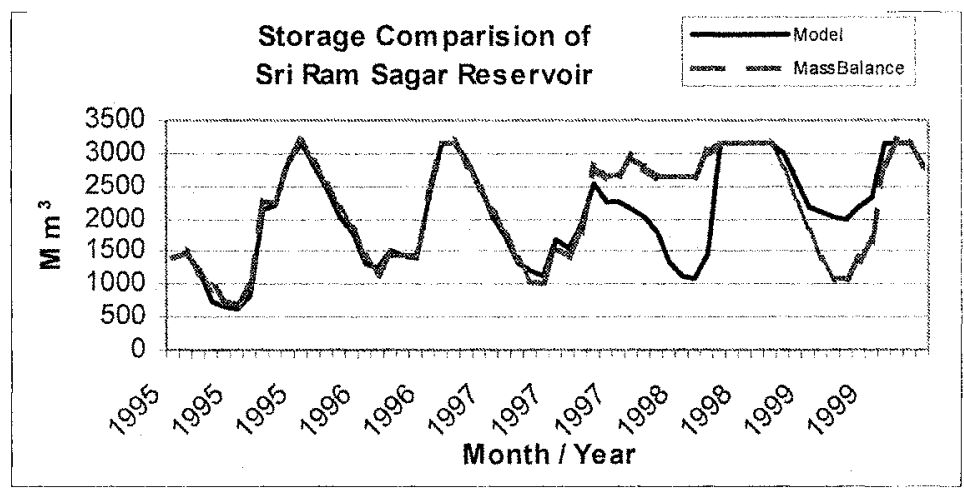

Fig 13. Variation of Storage Comparison at Sriramsagar 


\section{RESULTS AND CONCLUSIONS}

A fuzzy rule based model for multi purpose multi reservoir operation in long term was presented. The advantage of fuzzy rule based system that it utilizes the knowledge of a reservoir operator and avoids complex optimization procedure hence it may be more acceptable to the reservoir managers. Since the input operators are in linguistic terms it is easy to adopt and operation. The methodology was demonstrated with a case study of Nizamsagar and Sriramasagar reservoirs on Godavari system in Andhra Pradesh, India. The result shows the potential application of mapping the reservoir manager's expertise in simulating the two reservoirs studied. At Nizamsagar model failed 10 months to meet full water supply compared to 17 times historically for the period of simulation. Similarly it was found that at Sriramsagar model failed 6 months to meet full water supply compared to 12 times historically for the period of simulation. The annual hydropower production is improved by about $4 \%$ to $21.6 \%$ in four years compared to historical hydropower production at Nizamsagar reservoir and at Sriramasagar it was improved by $1.6 \%$ to $20.3 \%$ in four years. Irrigation performance seasonal wise was shown in figs 4 to 7 and 9 to 12 shows improvement in Kharief and Rabi seasons.

\section{REFERENCES}

[1] Cheng Chuntian (1999) Fuzzy optimal model for the flood control system of the upper and middle reaches of Yangtze River, Hydrological Sciences Journal Vol. 44 No 4. 573 585

[2] Labadie (2004) Optimal Operation of Multi Reservoir Systems: State-of-The-Art Review Journal of Water Resource Planning and Management Vol. 130 No. 2 pp 93-111

[3] Panigrahi \& Mujumdar (2000) Reservoir operation modeling with fuzzy logic, Journal of Water Resource Management No. 14 pp 89-109

[4] Shrestha et al (1996) A Fuzzy Rule based Reservoir operation, Journal of Water Resource Planning and Management Vol. 122 No 3. pp 262-268

[5] Savic and Simonovic (1991) Slecting risk levels in Chance-Constrained Reservoir Operation Modeling: A Fuzzy Set Approach, Journal of Water Resource Management No. 4 pp 251-271.

[6] Tanja Dubrovin et al (2002) Fuzzy Model for Real-Time Reservoir Operation, Journal of Water Resource Planning and Management Vol. 128 No 1 pp 66-73 